\title{
USO DO KINECT PARA MONITORAMENTO DE EXERCÍCIOS FíSICOS REALIZADOS POR PESSOAS DE TERCEIRA IDADE
}

\section{KINECT FOR MONITORING THE USE OF PHYSICAL EXERCISES PERFORMED BY ELDERLY}

Fábio Tadashi Kochi Tanji ${ }^{1}$, Francisco Assis da Silva ${ }^{2}$, Ana Paula Domeneghetti Parizoto Fabrin², Mário Augusto Pazoti ${ }^{2}$, Jair Rodrigues Garcia Júnior $^{3}$

${ }^{1}$ Discente da Faculdade de Informática da UNOESTE; ${ }^{2}$ Docente da Faculdade de Informática da UNOESTE; ${ }^{3}$ Docente da Faculdade de Educação Física da UNOESTE.

Correspondência para Francisco Assis da Silva - chico@unoeste.br

RESUMO - O constante crescimento da população idosa no Brasil e no mundo é um importante indicativo que as pessoas estão vivendo mais, mas não quer dizer que estão vivendo melhor. 0 processo de envelhecimento está atrelado a importantes perdas da capacidade do indivíduo, tanto das capacidades físicas como também das capacidades funcionais, levando a diminuição da independência do idoso. Estudando a literatura da área, é possível perceber que a prática de exercícios físicos contribui de maneira significativa para a manutenção da aptidão física do idoso. Neste trabalho foram realizados estudos a fim de identificar alternativas para auxiliar o idoso na prática de atividades físicas, por meio da inserção de recursos tecnológicos, como o sensor de movimentos Kinect, para acompanhar a realização dos exercícios, além de torná-la atrativa e motivadora.

Palavras-chave: Kinect; terceira idade; exercício físico.

Recebido em: 25/11/2013 Revisado em: 10/12/2013 Aprovado em: 29/01/2014

\begin{abstract}
The constant growth of the elderly population in Brazil and in the world is an important indication that people are living longer, but it doesn't mean they're living better. The aging process is linked to significant loss of a person's abilities, both physical and functional, leading to reduced independency of the elderly. Studying the related literature, it's possible to realize that physical exercise contributes significantly to the maintenance of physical fitness in the elderly. In this paper studies were made to look for new ways to help the elderly to exercise, taking into account the search for a resource that would be attractive and would motivate the elderly in physical activities.
\end{abstract}

Keywords: Kinect; elderly; physical exercise. 


\section{INTRODUÇÃO}

Com o crescimento da população de terceira idade é importante e necessário que haja uma preocupação constante em relação à saúde e ao bem estar do idoso. 0 processo de envelhecimento está atrelado a perdas importantes de inúmeras capacidades físicas, as quais culminam, inevitavelmente, no declínio da capacidade funcional e da independência do idoso (DIAS; GURJÃO; MARUCCI, 2006) (MATSUDO, 2002) (MATSUDO; MATSUDO; BARROS NETO, 2000). O fenômeno do envelhecimento da população levanta questões importantes, seja do ponto de vista pessoal ou socioeconômico, sendo elas interdependentes (VERAS, 2009). Dentre essas questões, a mais importante é saber se o ciclo de vida aumentado pode ser vivido com qualidade, ou se tratará apenas de um período de aumento de estados patológicos e de morbidade que precede a morte. Para que haja uma diminuição desse período de morbidade ou de estados disfuncionais prémorbidade, planos e programas que previnam tal situação devem ser criados. Dentre os mecanismos de prevenção, certamente a atividade física deve ser um componente importante, pois $\mathrm{O}$ envelhecimento associa-se, obrigatoriamente, à redução da capacidade aeróbica máxima, da força muscular e das respostas motoras mais eficientes, ou seja, à redução da aptidão física (OKUMA, 1998).

Segundo Alves et al. (2004), a prática de exercícios físicos, além de combater o sedentarismo e contribuir de maneira significativa para a manutenção da aptidão física do idoso, pode imediatamente produzir uma profunda melhora nas funções essenciais para a aptidão física do idoso, colaborando para que haja menor destruição de células e fadiga.

A proposta deste trabalho é utilizar a tecnologia como meio de se conseguir melhorar a qualidade de vida das pessoas da terceira idade. Utilizando o sensor Kinect, é possível auxiliar os idosos na prática de exercícios físicos e, ao mesmo tempo, monitorar se os movimentos que estão sendo executados estão corretos.

As demais seções deste trabalho estão organizadas da seguinte maneira: na Seção 2 é apresentado o sensor de movimentos Kinect e suas principais características; na Seção 3 são apresentadas informações sobre o monitoramento fisiológico; na Seção 4 são apresentadas a metodologia e o desenvolvimento da aplicação; na Seção 5 são apresentados os procedimentos; na Seção 6 são apresentados os experimentos realizados e, na Seção 7, encontra-se a conclusão deste trabalho. 


\section{SENSOR DE MOVIMENTOS KINECT}

O sensor de movimentos Kinect é um dispositivo físico que contém sensores capazes de capturar imagens coloridas, dados de profundidade, reconhecer o corpo de uma pessoa, sons e também é possível implementar softwares que processam cores, profundidade e dados do esqueleto do usuário. Ele foi desenvolvido pela Microsoft, a qual disponibiliza o Kinect Developer Toolkit e o Kinect SDK (Standard Development Kit) para desenvolvimento de aplicações que se comuniquem com o sensor.

Na Figura 1 é apresentado o sensor e indicados seus componentes, os quais dão a ele a capacidade de mapear pontos do corpo humano, mapear a distância de objetos e reconhecimento de voz. Os principais componentes do sensor Kinect são:
- Emissor de Infravermelho: responsável por emitir raios de luzes infravermelhos;

- Sensor infravermelho de profundidade: responsável por capturar os raios de luzes infravermelhos que foram refletidos de volta após emissão, o que possibilita calcular a distância entre o sensor e os objetos ao redor;

- Sensor colorido: responsável pela captura de imagens coloridas por meio de uma câmera RGB;

- Conjunto de microfones: responsável pela captura de som, sendo composto por quatro microfones;

- Motor de inclinação: responsável pelo ajuste do ângulo de inclinação do sensor.

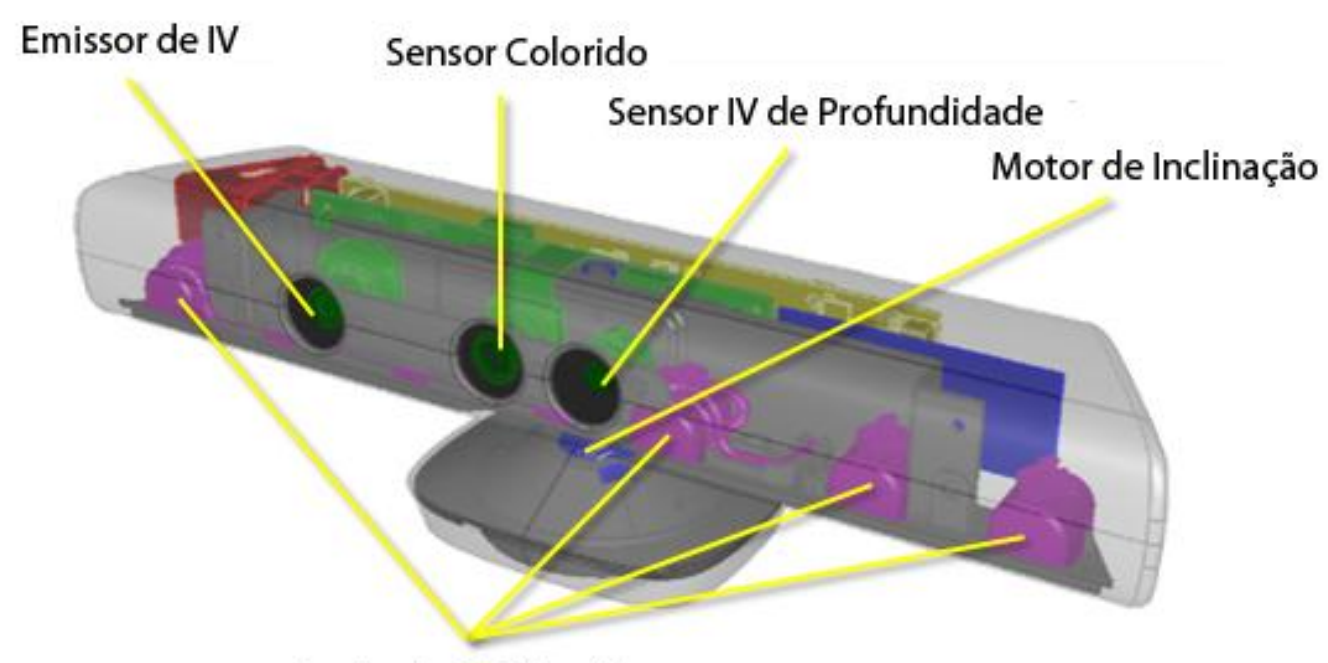

Conjunto de Microfones

Figura 1. Sensor de movimentos Kinect. 


\subsection{Pontos de mapeamento do Kinect}

O sensor de movimentos Kinect também tem a capacidade de mapear as articulações de até duas pessoas e detectar até seis pessoas, como mostrado na Figura 2(a). Para cada pessoa, o sensor tem a capacidade de mapear até 20 articulações no modo padrão, que é quando a pessoa está em pé (Figura 2 (b)) e até dez articulações da parte superior do corpo se a pessoa estiver sentada (Figura 2 (c)). Cada conjunto de articulações mapeado é denominado como esqueleto. Neste trabalho foi usado o mapeamento de apenas uma pessoa em pé, que é o modo padrão.

$\mathrm{Na}$ Figura 2(a) são mostrados os possíveis estados de mapeamento, os quais são:

- Tracked: quando o esqueleto foi mapeado corretamente e pode fornecer a posição das 20 articulações;
- Not Tracked: quando o esqueleto não foi mapeado;

- Position Only: quando o esqueleto possui apenas informações sobre a posição do usuário, mas não possui informações de suas articulações.

Além disso, cada uma das articulações também apresenta um estado de mapeamento, o qual pode ser:

- Tracked: quando a articulação está claramente visível;

- Not Tracked: em que a articulação não foi mapeada, por exemplo, no caso das articulações inferiores, quando a pessoa está sentada;

- Inferred: quando a articulação não está claramente visível e o Kinect está inferindo a posição.

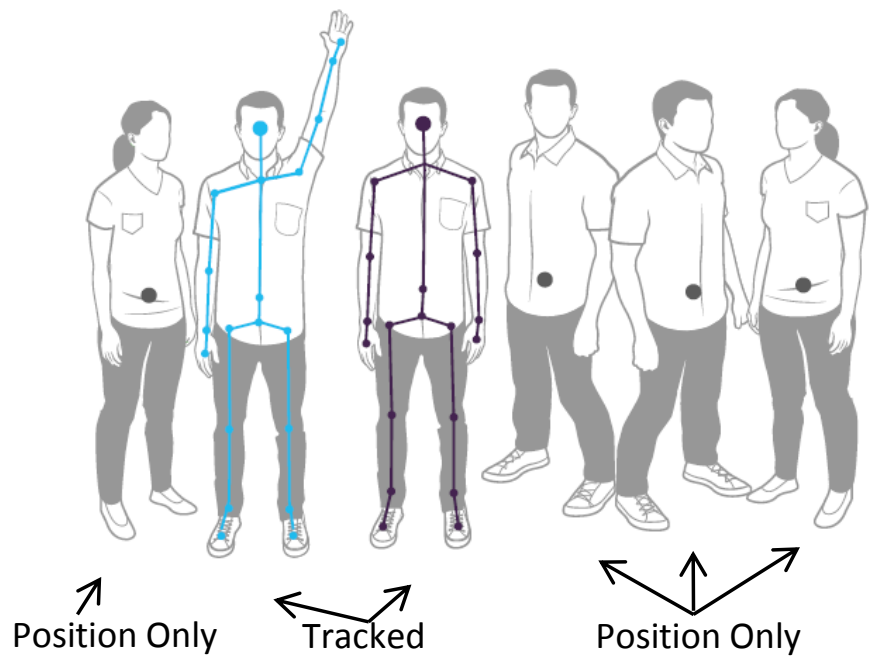

(a)

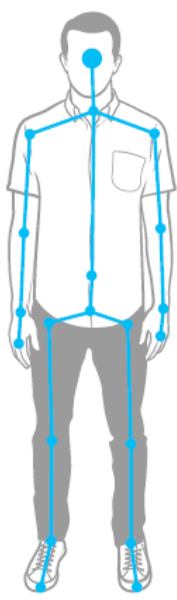

(b)

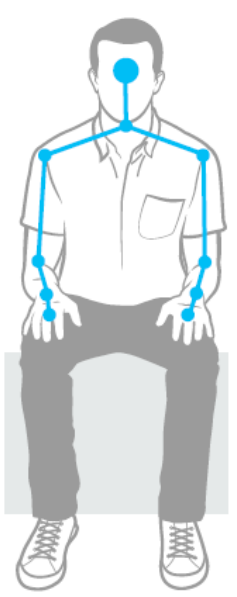

(c)

Figura 2. Pontos e capacidade de mapeamento do sensor Kinect. 


\section{DADOS FISIOLÓGICOS}

Para a realização dos exercícios físicos faz-se importante que o idoso possa acompanhar seu estado a partir de alguns dados fisiológicos, como, por exemplo, a frequência cardíaca. Esses dados se fazem necessários para que o praticante, de posse deles, tenha segurança na realização da atividade física.

\subsection{Frequência Cardíaca Máxima}

O débito cardíaco máximo tende a diminuir de forma linear, tanto nos homens quanto nas mulheres, após os trinta anos de idade. Isso se deve, sobretudo, à diminuição da frequência cardíaca máxima com a idade. A diminuição da frequência cardíaca máxima com a idade pode ser calculada usando a Equação em (1) (POWERS; HOWLEY, 2000).

$$
F C_{-} \text {Max }=220-\text { idade (anos) }
$$

A frequência máxima possibilita a definição da Zona de Treinamento, necessária para avaliar a eficiência e a realização da atividade física personalizada.

\subsection{Zona de Treinamento}

A zona de treinamento corresponde ao intervalo entre a frequência cardíaca (FC) de treinamento mínima e a frequência cardíaca de treinamento máxima. De acordo com McArdle (2011), a capacidade aeróbica melhora se a atividade física for de intensidade suficiente para fazer aumentar a frequência cardíaca até pelo menos $70 \%$ da frequência cardíaca máxima (FC_Max). As frequências cardíacas de treinamento mínima e máxima podem ser calculadas utilizando as Equações em (2).

$$
\begin{aligned}
& F C \text { _trein_min }=F C \_ \text {Max } * 0,50 \\
& F C_{-} \text {trein_max }=F C_{-} \text {Max }^{*} 0,70
\end{aligned}
$$

\section{METODOLOGIA}

Para este trabalho foram definidas algumas etapas, sendo a primeira 0 desenvolvimento do módulo capaz de armazenar os exercícios como templates, que posteriormente serão repetidos pelo idoso. Na segunda etapa foi definido o método de acompanhamento do exercício, de forma a possibilitar a avaliação do exercício realizado em comparação ao template previamente armazenado. Por fim, foi desenvolvida uma forma de apresentar uma pontuação que represente o desempenho do idoso na realização dos exercícios propostos.

Trata-se, portanto, de uma pesquisa aplicada qualitativa de cunho participativo, do autor deste projeto, sem, no entanto, testar os resultados em nível experimental com outros indivíduos.

\section{PROCEDIMENTOS}


Todo exercício físico executado na aplicação foi previamente cadastrado com a ajuda de um profissional da área. Durante a gravação do exercício, o sensor Kinect capturou a imagem colorida e o esqueleto com as articulações mapeadas, disparando um evento para processamento desses dados, o qual consistiu em: (i) verificar o estado de mapeamento do esqueleto; (ii) verificar o estado de mapeamento de cada articulação; e (iii) decidir se o esqueleto deveria ser guardado em memória ou descartado.

Todos os esqueletos com estado not tracked e position only foram descartados e somente os esqueletos com estado tracked foram utilizados para verificar se o estado de mapeamento da articulação era tracked ou inferred e, independentemente do estado, foram guardados em memória. Para cada articulação foi possível obter o valor de $X$ e $Y$ correspondentes às coordenadas de cada articulação mapeada na aplicação. Durante a gravação foi exibido o esqueleto, que teve suas articulações com estado tracked desenhadas na cor azul e as articulações com estado inferred desenhadas na cor amarela, possibilitando saber em tempo real se os movimentos estavam sendo cadastrados corretamente.

Primeiramente, os exercícios foram cadastrados desta maneira, em que apenas os pontos $X$ e $Y$ foram usados para o monitoramento do exercício. Após estudos sobre a execução dos exercícios em literatura da área, ficou claro que a maneira correta de se executar os exercícios dependia da angulação de cada articulação. Sendo assim, o cadastro foi implementado de maneira a exibir, durante a gravação, os ângulos das articulações, calculados por meio da Equação (3). Somente após o termino da gravação do exercício é que foi possível atribuir um nome ao exercício, atribuir o exercício a uma sessão e persistir os dados.

$$
\theta=\operatorname{arcos}\left[\frac{x a \cdot x b+y a \cdot y b}{\sqrt{x a^{2}+y a^{2}} \cdot \sqrt{x b^{2}+y b^{2}}}\right]
$$

Para a execução de um exercício, primeiramente a sessão e o exercício foram escolhidos, com ajuste livre da velocidade e precisão. $\mathrm{O}$ ajuste de precisão define qual a margem de erro que o aplicativo utiliza para a comparação entre o exercício executado e o exercício cadastrado. A margem de erro consiste na diferença de graus entre o exercício cadastrado e o executado. O intervalo de ajuste foi definido, empiricamente, entre um e dez.

Para o ajuste de velocidade definiu-se a quantidade de milissegundos necessários entre um estágio e outro, como taxa de atualização da imagem na tela. O ajuste de velocidade pode ter valores entre um e onze 
e, como são valores muito pequenos, foi usada a Equação (4) para se conseguir uma velocidade com valores mais confiáveis. Neste caso, vMax é a velocidade máxima e $v E s c$ é a velocidade definida.

Vel $=(((v M a x-v E s c)+1) * 20)$

Com os ajustes de precisão e de velocidade realizados foi possível iniciar a execução do exercício. Inicialmente o sensor Kinect procura por um esqueleto com estado Tracked, e assim que o encontra inicia a execução do exercício. Durante essa execução, é mostrado em tela o esqueleto do exercício escolhido sobreposto à imagem capturada pelo sensor Kinect em tempo real. Como o objetivo foi possibilitar que o movimento fosse realizado com as mesmas angulações de cada articulação do exercício gravado, tornou-se necessário centralizar o esqueleto e a pessoa capturada.

Para que isso fosse possível, a cada ciclo atualização do esqueleto foi calculada a média entre os pontos $Y$ centrais, que são as junções da cabeça (head), centro dos ombros (shoulder center), espinha (spine) e centro dos quadris (hip center) e calculados os mesmos dados dessas junções na imagem real. De acordo com a diferença obtida entre os dois, o esqueleto foi reposicionado sobre a imagem real. Durante a execução do exercício pôde-se saber se o exercício estava sendo executado de forma correta ou não em tempo real, por meio de indicações na tela.

Primeiramente, assim como no cadastro, foi pensado em monitorar a execução do exercício usando apenas a comparação dos pontos $X$ e $Y$ de cada articulação e o ajuste de precisão levava em consideração a distância dos pontos das articulações em relação ao modelo apresentado na tela. Para o cálculo da margem de erro aceitável, foi utilizada a fórmula de distância euclidiana, conforme a Equação (5). Após estudos, essa questão foi reavaliada e optou-se pela utilização dos ângulos das articulações para monitorar a execução dos exercícios. Toda a vez que o esqueleto foi desenhado na tela, os ângulos das articulações da imagem real e do esqueleto, previamente cadastrado (template), foram calculados e, levando em conta o ajuste de precisão, cada articulação era apresentada na cor verde, caso o ângulo estivesse dentro da margem de erro, ou na cor vermelha, caso contrário.

$$
d i s t=\sqrt{\left(x_{1}-x_{2}\right)^{2}+\left(y_{1}-y_{2}\right)^{2}}
$$

Após a execução de um exercício foi possível exibir o resultado com base no que foi executado pelo indivíduo, o qual consistiu 
em um conjunto de dados parciais composto pelo percentual de acerto de cada um dos vinte pontos do esqueleto e no resultado completo, em que foi possível apresentar, quadro a quadro, os movimentos executados e os movimentos que deveriam ser executados, por meio dos respectivos pontos $X$ e $Y$.

\subsection{Mapeamento dos Movimentos por Meio}

Como mencionado anteriormente, o mapeamento por meio dos ângulos foi a solução encontrada para monitorar os movimentos realizados pelo indivíduo na execução do exercício. Na Figura 3 foram enumeradas as articulações que podem ser capturadas pelo sensor Kinect. Nas Tabelas 1 e 2 são mostrados o nome da articulação e a relação dos respectivos ângulos utilizados no cadastro e monitoramento do exercício.

\section{de Ângulos}

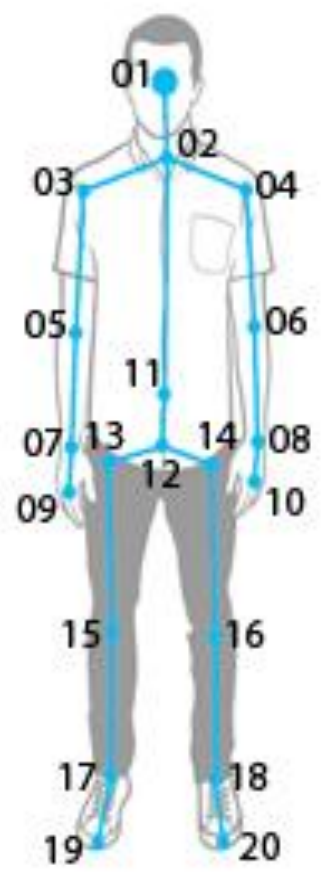

Figura 3. Articulações capturadas pelo sensor Kinect enumeradas.

Na Tabela 2 é mostrada na coluna "Ponto 1" as articulações em que foram calculados os ângulos, e nas colunas "Ponto 2" e "Ponto 3" os outros pontos para que fosse possível realizar esse cálculo. Observando a Tabela 2, também é possível verificar que as articulações da cabeça, mão esquerda, mão direita, centro dos quadris, pé direito e pé esquerdo não possuem a relação entre ângulos e articulações, pois para o cálculo do ângulo são necessários pelo menos três pontos, sendo o ponto central o da articulação que se deseja calcular. Como os pontos citados são de extremidades, eles 
Tabela 1. Nomes das articulações capturadas pelo sensor Kinect, de acordo com a Figura 8.

\begin{tabular}{|l|l|}
\hline № & \multicolumn{1}{|c|}{ Nome } \\
\hline 01 & Cabeça (head) \\
\hline 02 & Centro dos Ombros (shouldercenter) \\
\hline 03 & Ombro Esquerdo (shoulderleft) \\
\hline 04 & Ombro Direito (shoulderright) \\
\hline 05 & Cotovelo Esquerdo (elbowleft) \\
\hline 06 & Cotovelo Direito (elbowright) \\
\hline 07 & Pulso Esquerdo (wristleft) \\
\hline 08 & Pulso Direito (wristright) \\
\hline 09 & Mão Esquerda (handleft) \\
\hline 10 & Mão Direita (handright) \\
\hline 11 & Coluna Vertebral (spine) \\
\hline 12 & Centro dos Quadris (hipcenter) \\
\hline 13 & Quadril Esquerdo (hipleft) \\
\hline 14 & Quadril Direito (hipright) \\
\hline 15 & Joelho Esquerdo (kneeleft) \\
\hline 16 & Joelho Direito (kneeright) \\
\hline 17 & Tornozelo Esquerdo (ankleleft) \\
\hline 18 & Tornozelo Direito (ankleright) \\
\hline 19 & Pé Esquerdo (footleft) \\
\hline 20 & Pé Direito (footright) \\
\hline
\end{tabular}

Tabela 2. Relação dos pontos utilizados para calcular os ângulos de cada articulação.

\begin{tabular}{|l|l|l|}
\hline \multicolumn{3}{|c|}{ Relação Ângulos x Articulações } \\
\hline \multicolumn{1}{|c|}{ Ponto 1 } & \multicolumn{1}{|c|}{ Ponto 2 } & \multicolumn{1}{c|}{ Ponto 3 } \\
\hline Cabeça & - & - \\
\hline Centro dos Ombros & Cabeça & Coluna Vertebral \\
\hline Ombro Esquerdo & Centro dos Ombros & Cotovelo Esquerdo \\
\hline Ombro Direito & Centro dos Ombros & Cotovelo Direito \\
\hline Cotovelo Esquerdo & Ombro Esquerdo & Pulso Esquerdo \\
\hline Cotovelo Direito & Ombro Direito & Pulso Direito \\
\hline Pulso Esquerdo & Cotovelo Esquerdo & Mão Esquerda \\
\hline Pulso Direito & Cotovelo Direito & Mão Direita \\
\hline Mão Esquerda & - & - \\
\hline Mão Direita & - & - \\
\hline Coluna Vertebral & Coluna Vertebral & Centro dos Quadris \\
\hline Centro dos Quadris & - & - \\
\hline Quadril Esquerdo & Centro dos Quadris & Joelho Esquerdo \\
\hline Quadril Direito & Centro dos Quadris & Joelho Esquerdo \\
\hline Joelho Esquerdo & Quadril Esquerdo & Tornozelo Esquerdo \\
\hline Joelho Direito & Quadril Direito & Tornozelo Direito \\
\hline Tornozelo Esquerdo & Joelho Esquerdo & Pé Esquerdo \\
\hline Tornozelo Direito & Joelho Direito & Pé Direito \\
\hline Pé Esquerdo & - & - \\
\hline Pé Direito & - & - \\
\hline
\end{tabular}




\subsection{Estrutura física}

Para testar o funcionamento do aplicativo desenvolvido neste trabalho, uma estrutura física foi criada. Essa estrutura teve por objetivo, além de permitir a realização de testes da aplicações, se comunicar com a aplicação que coleta os dados fisiológicos, desenvolvida por (LIMA et al., 2013). A aplicação envia em tempo real, por meio de web service, os dados sobre um indivíduo como altura, peso, idade, frequência cardíaca e zona de treinamento, e os dados em

relação ao exercício físico como frequência cardíaca e gasto calórico, os quais auxiliam no monitoramento durante a execução dos exercícios físicos. O web service foi executado em um iPhone, juntamente ao aplicativo que monitora os dados fisiológicos do indivíduo. Para que fosse possível receber os dados por meio do web service, o computador em que o aplicativo desenvolvido neste trabalho estiver sendo executado deverá estar na mesma rede que o iPhone, conforme Figura 4.

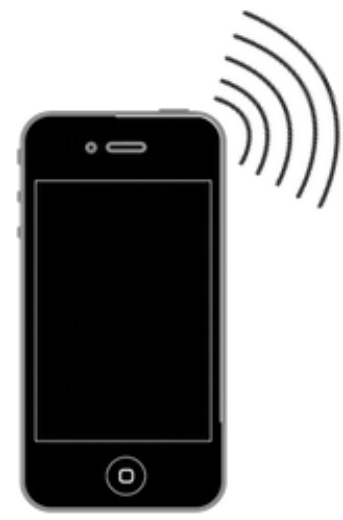

iPhone

Endereço IP: 172.16.0.12 Máscara: 255.255.255.0

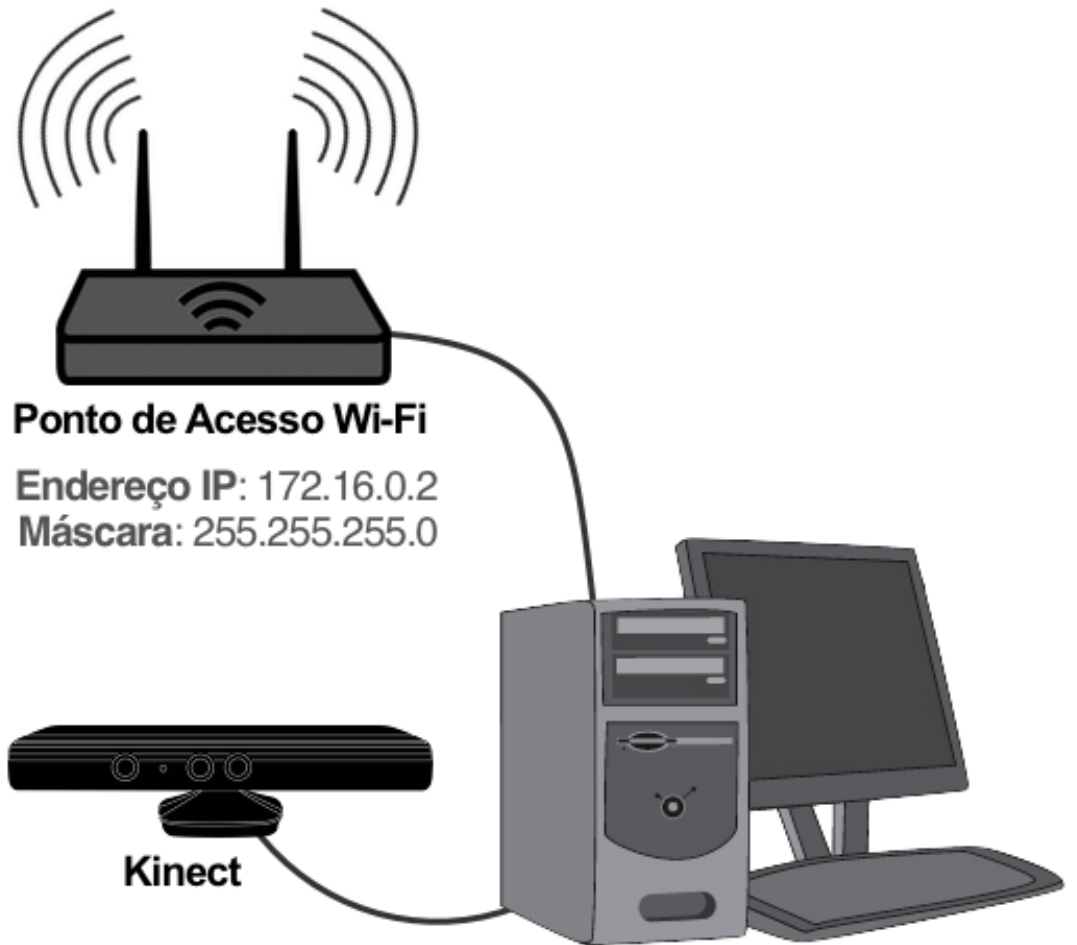

Computador Máscara: 255.255.255.0

Figura 4. Estrutura física para recebimento de dados por meio de um web service.

Mesmo tendo sido solicitado os dados, pelo web service, esta aplicação utilizou apenas aqueles referentes à idade e à frequência cardíaca. Com a idade, é possível 
definir a frequência cardíaca máxima e com a frequência cardíaca, juntamente com a frequência cardíaca máxima, é possível definir a zona de treinamento.

A partir da zona de treinamento definida, foi possível ajustar a frequência cardíaca dentro da zona de treinamento ou abaixo da mesma. Isto foi possível porque sempre que a frequência ficar acima da zona de treinamento, a aplicação vai diminuindo a velocidade até chegar à velocidade mínima permitida pelo ajuste. Como este monitoramento de frequência cardíaca é apenas para auxiliar e é necessário que a aplicação do iPhone também esteja sendo executada, o próprio usuário precisa parar a execução do exercício físico caso a frequência cardíaca permaneça acima do permitido.

Para ser possível o envio de dados do iPhone para o web service e a solicitação dos dados pelo computador onde está ligado o sensor Kinect, é preciso que o web service tenha a estrutura das Figuras 5, 6 e 7.

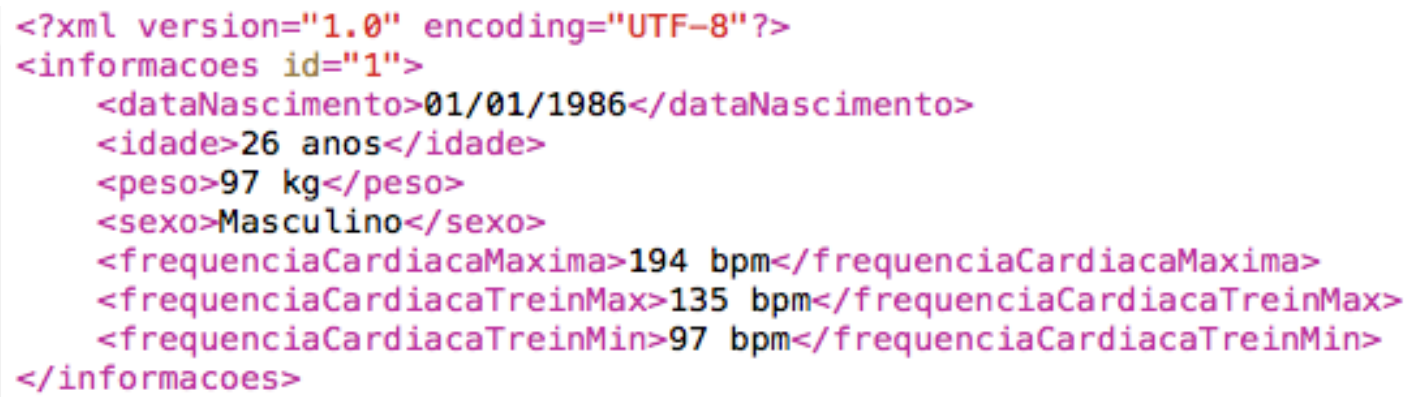

Figura 5. Dados referente ao usuário

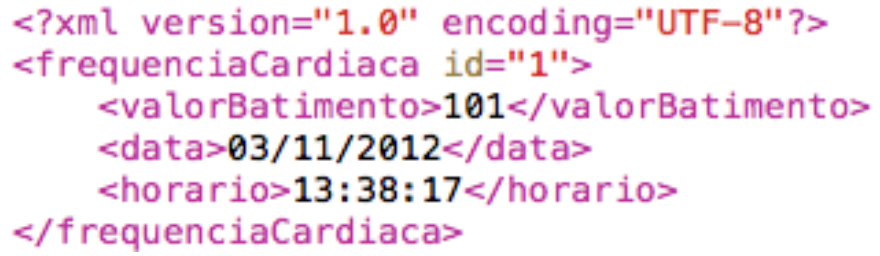

Figura 6. Dados referente a frequencia cardíaca.

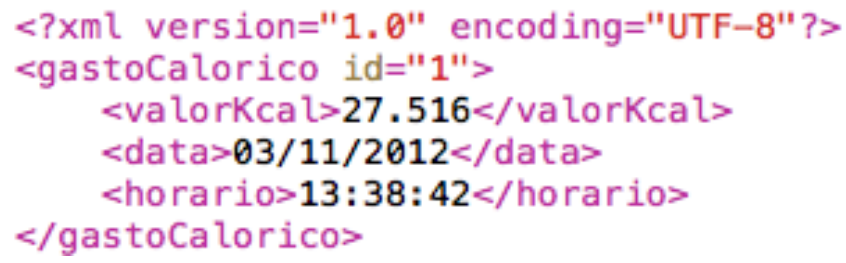

Figura 7. Dados referente ao gasto calórico 
perdidos sempre que a aplicação for reiniciada, foi necessário que os dados fossem persistidos em um banco de dados. Com a persistência, é possível que os exercícios sejam recuperados sempre que necessário. O banco de dados utilizado para a persistência dos dados foi o Microsoft SQL Server 2008, que possui o modelo lógico conforme mostrado na Figura 3.

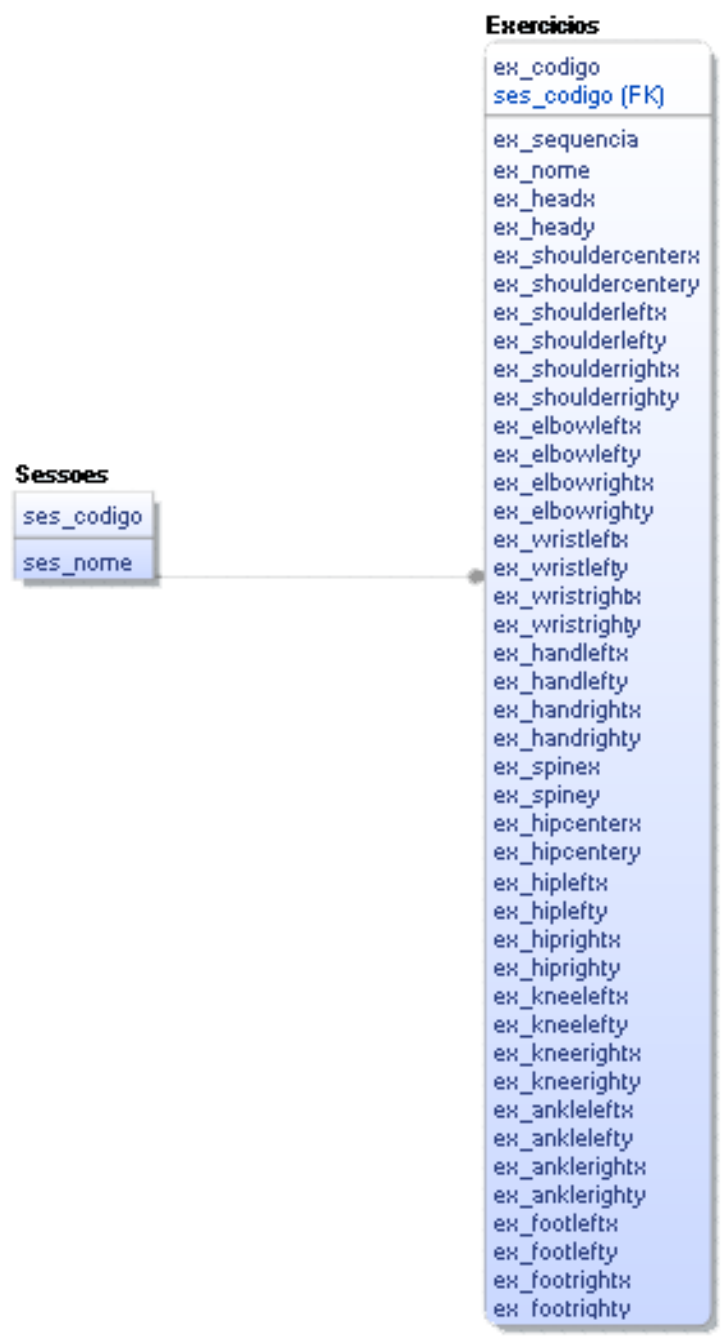

Figura 8. Modelo lógico do banco de dados.

\section{EXPERIMENTOS}

Foram realizados, neste trabalho, experimentos para verificar funcionamento do aplicativo, se as imagens do sensor Kinect estão sendo exibidas e capturadas de maneira correta, se os cálculos estão corretos e se os resultados estão coerentes durante a execução do aplicativo.

Para a execução dos experimentos, primeiramente foram gravados três exercícios para que pudessem ser executados os experimentos necessários. Para a escolha dos exercícios e para que os exercícios 
fossem gravados de forma correta, foi solicitada a ajuda de um profissional da área de educação física.

Os exercícios utilizados para o experimento estão dispostos como abaixo:

- Exercício 01: Indivíduo em pé, com os braços cruzados e apoiados nos ombros opostos. Pés afastados. Mantendo a coluna ereta, o sujeito abaixa (agacha) até que sua coxa fique na posição horizontal (angulo de 90 graus em relação ao tronco). Em seguida volta à posição inicial e repete 10 vezes o movimento. Inspira quando desce e expira quando sobre;

- Exercícios 02: Indivíduo em pé, com os braços estendidos ao lado do corpo. Pés afastados. Mantendo a coluna ereta, o sujeito levanta os dois braços estendidos à frente, na linha dos ombros, até que fiquem na posição vertical (ângulo de 180 graus em relação ao tronco). Em seguida volta à posição inicial, abaixando-os lentamente. Inspira quando desce e expira quando sobre;

- Exercícios 03: Indivíduo em pé, com os braços estendidos ao lado do corpo. Pés afastados. Mantendo a coluna ereta, o sujeito levanta os dois braços lateralmente ao tronco, até que fiquem na posição vertical (ângulo de 180 graus em relação ao tronco). Em seguida volta à posição inicial, abaixandoos lentamente. Inspira quando desce e expira quando sobre.

\section{RESULTADOS}

A partir dos experimentos realizados, foi constatado que existem algumas limitações e que nem todos os tipos de exercícios físicos foram possíveis de serem cadastrados de forma correta. Como todas as partes do sensor Kinect não consegue visualizar claramente e são marcadas com o estado de inferred -- significando que o sensor Kinect não conseguiu visualizar e mapear corretamente, inferindo o valor --, movimentos em que um membro ficou sobreposto a outro não foram necessariamente cadastrados corretamente. Também não foi possível cadastrar exercícios onde o indivíduo tenha que ficar de perfil e, consequentemente, metade do corpo não ficou visível ao sensor Kinect ou que tenha rotações onde algum membro não tenha ficado visível.

Durante os testes com o Exercício 01, foi constatado que não era possível cadastrálo de forma correta, pois no movimento de agachar o sensor Kinect não conseguiu mapear corretamente as articulações. Com o exercício 02 também não foi possível mapear corretamente a parte em que os braços estendidos são levantados á frente. Já no Exercício 03, foi possível cadastrar o exercício corretamente e a partir disso, foi executado o exercício e constatado que os ângulos estavam sendo calculados corretamente e que a mudança do esqueleto para verde ou vermelho, dependendo se estava sendo 
executado de forma certa ou errada, funcionava perfeitamente.

A Tabela 3 mostra os dados capturados durante a execução do Exercício 03 e a Figura 9 mostra o esqueleto referente ao dados da Tabela 3, onde o esqueleto (a) é o exercício que foi salvo e o esqueleto (b) como estava sendo executado. Observando os dados da Tabela 3, na coluna A, e levando em consideração que o ajuste de precisão estava no nível 10 , foi possível constatar que os ângulos de todas as articulações calculadas estavam dentro no esperado.

Tabela 3. Resultados

\begin{tabular}{|l|c|c|c|c|c|c|}
\hline & \multicolumn{3}{|c|}{ Gravado } & \multicolumn{3}{c|}{ Executado } \\
\hline & $\mathrm{X}$ & $\mathrm{Y}$ & $\mathrm{A}$ & $\mathrm{X}$ & $\mathrm{Y}$ & $\mathrm{A}$ \\
\hline Cabeça & 351 & 90 & - & 348 & 90 & - \\
\hline Centro dos Ombros & 355 & 135 & $\mathbf{1 7 4}$ & 356 & 136 & $\mathbf{1 7 0}$ \\
\hline Ombro Esquerdo & 312 & 160 & $\mathbf{1 7 2}$ & 312 & 160 & $\mathbf{1 7 4}$ \\
\hline Ombro Direito & 394 & 161 & $\mathbf{1 7 1}$ & 396 & 162 & $\mathbf{1 7 2}$ \\
\hline Cotovelo Esquerdo & 266 & 179 & $\mathbf{1 7 6}$ & 266 & 180 & $\mathbf{1 7 9}$ \\
\hline Cotovelo Direito & 444 & 185 & $\mathbf{1 7 4}$ & 447 & 186 & $\mathbf{1 7 8}$ \\
\hline Pulso Esquerdo & 216 & 196 & $\mathbf{1 6 9}$ & 218 & 200 & $\mathbf{1 7 0}$ \\
\hline Pulso Direito & 501 & 206 & $\mathbf{1 8 0}$ & 494 & 207 & $\mathbf{1 7 6}$ \\
\hline Mão Esquerda & 200 & 205 & - & 199 & 212 & - \\
\hline Mão Direita & 520 & 213 & - & 515 & 215 & - \\
\hline Coluna Vertebral & 355 & 220 & $\mathbf{1 7 6}$ & 356 & 213 & $\mathbf{1 7 5}$ \\
\hline Centro dos Quadris & 356 & 235 & - & 357 & 226 & - \\
\hline Quadril Esquerdo & 338 & 253 & $\mathbf{1 4 1}$ & 341 & 245 & $\mathbf{1 4 9}$ \\
\hline Quadril Direito & 374 & 253 & $\mathbf{1 4 9}$ & 374 & 245 & $\mathbf{1 4 8}$ \\
\hline Joelho Esquerdo & 328 & 335 & $\mathbf{1 7 3}$ & 324 & 344 & $\mathbf{1 7 5}$ \\
\hline Joelho Direito & 395 & 332 & $\mathbf{1 7 9}$ & 391 & 343 & $\mathbf{1 7 6}$ \\
\hline Tornozelo Esquerdo & 311 & 405 & $\mathbf{1 5 4}$ & 308 & 408 & $\mathbf{1 5 6}$ \\
\hline Tornozelo Direito & 415 & 406 & $\mathbf{1 7 4}$ & 398 & 406 & $\mathbf{1 7 3}$ \\
\hline Pé Esquerdo & 315 & 424 & - & 311 & 427 & - \\
\hline Pé Direito & 422 & 425 & - & 403 & 428 & - \\
\hline
\end{tabular}

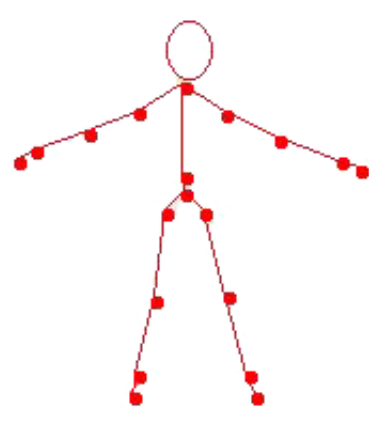

(a)

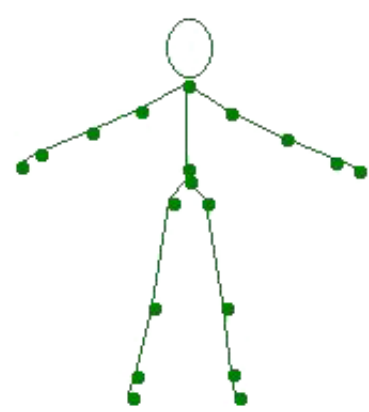

(b)

Figura 9. Desenho do esquiucleto referente à Tabela 3. 
Apesar das limitações citadas, foi possível escolher apenas exercícios que o sensor Kinect tenha sido capaz de mapear corretamente.

\section{CONCLUSÃO}

Com este trabalho foi possível constatar que, apesar de algumas limitações, pode-se utilizar os recursos tecnológicos para auxiliar a prática de atividades físicas por pessoas de terceira idade de uma maneira mais segura, e assim contribuir para a melhoria da qualidade de vida dos mesmos.

É importante lembrar que o aplicativo desenvolvido neste trabalho é apenas uma ferramenta para auxiliar na prática das atividades física e, em momento algum, substitui o profissional da área.

\section{REFERÊNCIAS}

ALVES, R.V. et al. Aptidão física relacionada à saúde de idosos: influência da hidroginástica. Revista Brasileira de Medicina do Esporte, v.10, n.1, jan/fev. 2004. Disponível em: http://www.scielo.br/pdf/rbme/v10n1/03.pd f. Acesso em: 06 mar. 2012.

DIAS, R.M.R.; GURJÃO, A.L.D.; MARUCCI, M.F.N. Benefícios do treinamento com pesos para aptidão física de idosos. Acta Fisiátrica, v.13, n.2, p.90-95, 2006. Disponível em: <http://actafisiatrica.org.br/v1\%5Ccontrole/s ecure/Arquivos/AnexosArtigos/92CC227532D 17E56E07902B254DFAD10/editoracao_vl_13 _n_02_90-95.pdf>. Acesso em: 06 mar. 2012.
LIMA, M.R. et al. Utilização dos recursos do iOS para Monitorar Pessoas de Terceira Idade na prática de Atividades Físicas. Colloquium Exactarum, v.5, n.2, 2013.

MATSUDO, S.M. Envelhecimento, atividade física e saúde. 2002. Disponível em: $<$ files.adrianobelem.webnode.com.br/20000 0198-01b5c02afc/envelhecimento-atividadefisica-e-saude.pdf>. Acesso em: 26 abr. 2012.

MATSUDO, S.M.; MATSUDO, V.K.R.; BARROS NETO, T.L. Impacto do envelhecimento nas variáveis antropométricas, neuromotoras e metabólicas da aptidão física. 2000. Disponível em: $<$ http://portalsaudebrasil.com/artigospsb/id oso086.pdf>. Acesso em: 26 abr. 2012.

MCARDLE, W. D.; KATCH, F. I.; KATCH, V. L. Fisiologia do Exercício: Nutrição, Energia e Desempenho Humano. 7ạ Edição. Editora Guanabara Koogan. 2011.

OKUMA S.S. 0 idoso e a atividade física: fundamentos e pesquisa. 4. ed. Campinas: Papirus, 1998.

POWERS, S. K.; HOWLEY, E. T. Fisiologia do Exercício: Teoria e Aplicação ao Condicionamento e ao Desempenho. 3a Edição. Editora Manole Ltda., 2000. 527 p.

VERAS, R. Envelhecimento populacional contemporâneo: demandas, desafios e inovações. 2009. Disponível em: <http://www.scielosp.org/pdf/rsp/v43n3/22 4.pdf>. Acesso em: 26 abr. 2012. 